\title{
Can Nigeria Attain a Demographic Dividend?
}

\author{
R. Scott Moreland \\ 401 Meadowmont Village Circle \\ Chapel Hill, NC 27517, USA
}

\begin{abstract}
We used a demographic-economic simulation model to explore the possibility of Nigeria obtaining a demographic dividend. The model, called, "DemDiv", has been applied in several other sub-Saharan African countries. Four scenarios were constructed and their results compared in terms of the level of GDP and GDP per capita in the final year of the simulation. GDP in the final year (2050) is I.6\% higher and GDP per capita is $27 \%$ higher under a scenario in which a successful family planning program is implemented. The modelling results suggest that Nigeria can enter the ranks of lower middle income economies and obtain a demographic dividend if it adopts appropriate family planning, education and economic strategies.
\end{abstract}

Key words: demographic dividend, population growth, model, Nigeria, family planning

\section{Introduction}

The relationship between demographic change and the economy is as old as Malthus and economists have long debated whether population growth hampers or hinders economic growth. (See for example, Kelly, 1985 and King, 1985, McNicoll, 1984 and National Academy of Sciences, 1986). The literature around the demographic dividend is the latest addition to this discussion. Advocates for stronger family planning programs have seized on the concept in their advocacy. (See Gribble and Bremner, 2014) There are several potential paths by which demographic changes can lead to an economic dividend, but the main linkage with the economy is through the age structure. As a demographic transition progresses, the ratio of the working-age population to the non-working young population increases. The recent paper by Ashraf et al. (20/3) outlines four linkages: First a dependency effect of a lower dependency ratio which increases per capita incomes. Second, a life-cycle savings effect of a larger working population which increases savings and investment. Third, an experience effect of increased productivity among an older, more experienced workforce. Fourth, a life-cycle labour supply effect of higher labor force participation rates among older workers. The labor supply effect may also be reinforced by an increase in women's labor force participation engendered by lower fertility rates. In addition to these age structure-driven effects, the authors describe several other economic benefits of population change more broadly, relating to the care of and investments in children, economies of scale, diminished pressure on fixed resources, and a lower capital-to-labor ratio ("capital shallowing").
The relationship between demographic change and the economy is as old as Malthus and economists have long debated whether population growth hampers or hinders economic growth. (See for example, Kelly, 1985 and King, 1985, McNicoll, 1984 and National Academy of Sciences, 1986). The latest concept to link population and economic growth is the "demographic dividend." First identified as a factor enhancing economic growth in Asia by Bloom and Willianson (Bloom, D.E. and Williamson, J.G., 1998), it has been suggested that the demographic dividend can help African countries boost their economic development. (Bloom et.al, 2014) The demographic dividend refers to a period when economic growth can potentially result from shifts in a population's age structure when the share of the working-age population (15 to 64) grows relative to the non-working-age share (14 and younger, and 65 and older). The "window of opportunity" for a dividend is initiated by a demographic transition caused by a fall in the fertility rate when a country goes from having high fertility and high mortality to having low fertility and low mortality.

However, the demographic transition, while necessary, is not a sufficient condition to engender a demographic dividend. For the dividend to be realized, research has shown (Drummond, P., Thakoor, V., \& Yu, S., 2014) that supporting socioeconomic policies must accompany the demographic transition. These include economic strategies and education, health, governance, labour and employment policies.

Also, in recent years the concept of the demographic dividend has become increasingly popular among policymakers in Africa. The 
Ministerial Statement published during the 20/3 meeting of African Union Ministers of Finance included a section noting, "the importance for Africa to introduce immediate measures to capitalize on its demographic dividend, through increased and sustained investments in health and education, particularly for women, the girl-child, the youth and disadvantaged social groups" (United Nations and African Union, 20I3). With its clear ties to economic growth, the demographic dividend has consolidated interest in population issues among policymakers whose priorities lie outside the health realm. This has built support for integrated, multisectoral development interventions ranging from family planning (FP) to job creation for young people. In addition, the 2012 London Family Planning Summit created renewed momentum for family planning, as donors and developing countries committed to support 120 million new contraceptive users by 2020. To ensure that these new Family Planning 2020 (FP2020) commitments are fully country-owned and viewed as national priorities, supporters must strengthen engagement with policymakers beyond the health sector and establish clear linkages between FP investments and overarching development goals. The demographic dividend is a clear opportunity to demonstrate how population changes motivated by FP policies and programs amplify the impact of other necessary development initiatives in employment, education, health, and the macroeconomic environment.

However, the demographic transition, while a necessary, is not a sufficient condition to engender a demographic dividend. For the dividend to be realized, research has shown (Drummond, P., Thakoor, V., \& Yu, S., 2014) that supporting socioeconomic policies must accompany the demographic transition. These include economic strategies and education, health, governance, labour and employment policies.

Since the relationships between demographic change and economic growth are complex and dynamic and since it is acknowledged that for a demographic dividend to be realized it must be accompanied by other supporting social and economic policies, a policy tool can be helpful to policy makers in designing a multi-sector approach. The model we developed and use in this paper is one such approach.

Recent demographic and economic trends in Nigeria

Nigeria is potentially ripe to reap a demographic dividend, if conditions can be put in place. While fertility is lower than in the past, the demographic transition has been slow in coming. In 2003, the total fertility rate was 5.7 and ten years later in 2013, it remained at 5.5 (NDHS, 20/3). Contraceptive prevalence in 2013 stood at 15.1 compared to 12.6 ten years earlier in 2003, an increase of only 0.25 points per year. The population in 2015 is $48 \%$ higher than in 2000.. (UN Population)

With a GDP that is among the top 25 in the world, Nigeria's per capita GDP was $\$ 2310$ in 2010. (World Bank.) In 1960 Nigeria's GDP per capita was $\$ 92$ similar to that of Thailand $(\$ 100)$, while in 2010 the GDP per capita for Thailand was twice that of Nigeria. During this same period, the population of Nigeria increased 2.5 fold compared to 1.4 in Thailand. Despite this lack of progress, economically, Nigeria still has immense potential because of its size and natural resources, especially oil. There are many reasons that might explain why Nigeria has not lived up to its economic potential until recently. Some of this may be due to poor economic management and political challenges, but some of it is also due to the high rate of population growth and the resulting young age distribution.

\section{Models of the demographic dividend}

Approaches to studying the demographic dividend have included the use of simulation models which estimate the potential dividend in countries where the necessary demographic conditions are not yet in place. For example, Ashraf's simulation model (Ashraf et. al., 20I3) looks at the impact of changes in fertility on output per capita. More recently, an econometric model was developed at the International Monetary Fund (Drummond et.al. 2014) which estimates the potential size of the dividend for sub-Saharan Africa. The model finds results similar to those of Bloom et.al, for the effects of changes in the working age population on real per capita GDP growth in Sub Saharan Africa.

There are also a few recent models that have been applies to Nigeria. Bloom (Bloom et. al. 2013 and 20I4, World Economic Forum, 2014) applied a model to Nigeria which was empirically established from cross-country economic growth equations. It showed significant impacts on GDP per capita of reducing the unmet need for family planning. Canning (Canning et.al. 2015) used data from Nigeria to construct a macro-simulation model based on the Ashraf et al. framework (Ashraf, 20I3), in which the evolution of key economic and demographic outcomes are observed under a "baseline" scenario, where fertility falls slowly over time, and are then compared to alternative scenarios in which fertility declines more rapidly. Under the scenarios they constructed, income per capita was $\$ 3261$ higher in 2050 with lower fertility than with higher fertility. Lastly, Mason et.al. (Mason et.al.2016) used a model with Nigerian data to estimate the impact of alternate 
fertility scenarios on per capita consumption. They found that a "radical" scenario in which replacement level fertility is reached by 2045 , increased the annual rate of growth of consumption by more than 1.4 percentage points compared with no fertility change.

In a scenarios with a more modest fertility decline in which replacement level fertility is reached towards the end of the century, the increase in annual per capita consumption growth is only 0.4 percentage points above the no change scenario.

While these models clearly demonstrated that Nigeria could potentially experience a demographic dividend when fertility declines, they lack the policy level detail in non-demographic areas that would allow for policies to be adopted to achieve the dividend. The model which we developed and use in this paper to explore the demographic dividend is a policy analysis tool that is more user-friendly and comprehensive than existing models and has been applied in over a dozen sub-Sharan African countries.

\section{Modelling a demographic dividend in Nigeria}

To understand the conditions under which Nigeria might benefit from a demographic dividend, we applied a new modelling tool developed by Futures Group's Health Policy Project, (Moreland. et.al., 2014) the "DemDiv" model. The model is composed of a demographic sub-model and an economic sub-model. See Figure I. The model structure reflects the nature of the demographic dividend as an opportunity created by demographic change and the dividend itself as an economic benefit. The DemDiv model used a statistical approach, including multiple linear regressions estimated from a cross-national data base for over 100 countries, to and used as inputs to the economic model. project demographic and economic changes. The demographic sub-model projects fertility, life expectancy at birth, child mortality and population size and age structure, including the dependency ratio. Policy variables that impact directly demographic variables include the proximate determinants of fertility such as the contraceptive prevalence rate (CPR), natural sterility and postpartum insusceptibility (PPI.) Girls' education also affects marriage and thus fertility.

These demographic calculations feed into the economic sub-model, which consists of equations projecting capital formation, employment growth and total factor productivity as a function of age structure and other social and economic variables. Economic policy variables included in the model were drawn from the World Economic Forum's Global Competitive Report (REF). We included indicators for ffinancial market efficiency, ICT infrastructure, the quality of public institutions, openness to trade as measured by imports, labor market flexibility.

The two-part model's sub-models interact over the projection period to describe the combined effects of changes in both sub-models, ultimately projecting GDP and GDP per capita. The model works on a platform in Microsoft Excel with a dynamic link to the cohort-component population projection model, DemProj, in Spectrum (REF.) Given values of the proximate determinants of fertility, the Excel model calculates fertility and life expectancy at birth which are passed to DemProj to project the population by age and sex. The population projections are then fed back into the Excel model

Figure I: Model Structure

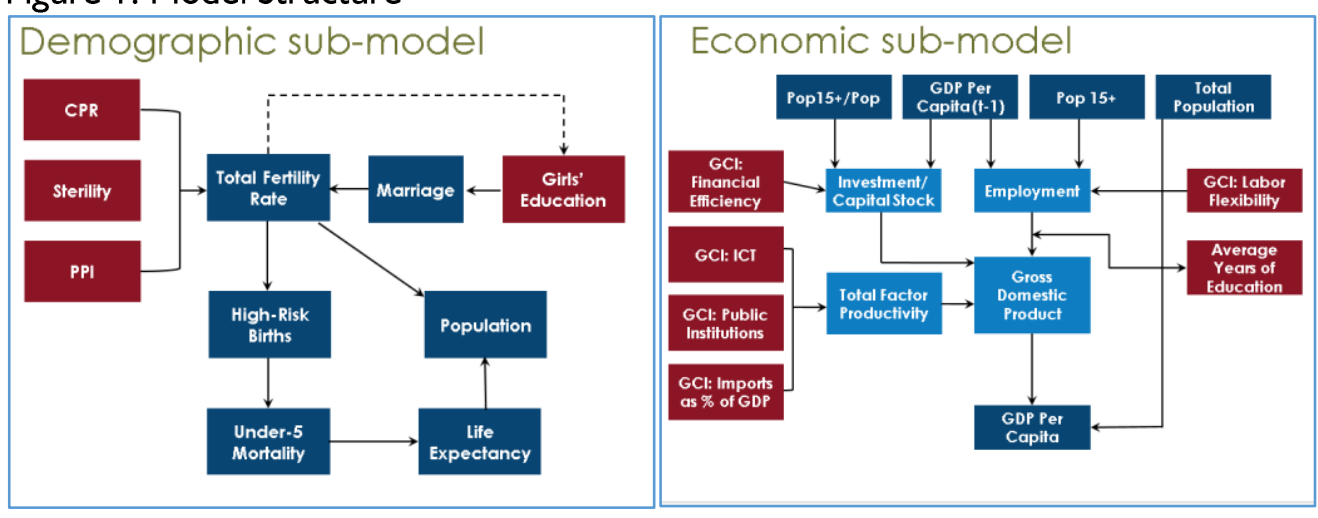

When applied to a specific country, users can input different scenarios based on their specific goals for the policy variables. Users can choose to design multiple scenarios to see the effects of different policies by manipulating the following variables:

- Contraceptive prevalence rate (CPR)
Postpartum insusceptibility Sterility Education Public institutional quality

- Labour market flexibility

- Financial market efficiency

- Imports 
- Information and communication technologies (ICT) infrastructure

We use the DemDiv model to simulate four scenarios of interacting policy changes. The simulations require target values for the policy indicators for the final year of the projection (2050). As shown in Tables $2 \mathrm{~A}-2 \mathrm{C}$ the policy indicators cover education, the proximate determinants of fertility (including family planning), and five indices from the World Economic Forum's Global Competitiveness Report. (Klaus Schwab and Xavier Sala-i-Martín, 2013). Each scenario is defined by the trajectory of these indicators as they progress from a base year value to a user-specified target value in the final year of the simulaton. Linear interpolation is used to calculate the values of years between the base and final years.

For the education indicators, we chose to use the current values of the indicators in Botswana as targets. For family planning, we set the 2050 target at a modern CPR of $65 \%$. We set aspirational targets for economic policy variables based on the average values for countries in either stage 2 or stage 3 as reported in the Global Competitiveness Report.

The four scenarios can be summarized as:

- A base scenario reflects continued slow progress in the expansion of family planning use, educational attainment and economic reforms. In this scenario, Nigeria attains just $30 \%$ of the education and economic goalposts of its targets. Family planning use increases to a level that eliminates the current level of unmet need $(16 \%)$ by 2050

- An economic emphasis scenario shows Nigeria achieving improvements in labour market flexibility, ICT use, financial market efficiency, public institutions and imports, roughly equivalent to the current average for stage 2 or stage 3 countries in the $\mathrm{GCl}$ report (see Figure I). Education and family planning are held constant as per the base scenario.

- An economic emphasis plus education scenario represents increased investments in education (reaching Botswana's current education levels) along with the improvements encompassed in the economic emphasis scenario.

- A combined economic, education and family planning scenario combines intensified investments in family planning with the education and economic emphasis scenarios. The modern CPR increases to $65 \%$ in this scenario. However, we decreased the PPI parameter from 12.6 months to 9 months to emulate the situation in 2013 in Lagos for this parameter.

The assumptions built into the four scenarios are shown in Tables $2 \mathrm{~A}, 2 \mathrm{~B}$ and $2 \mathrm{C}$.

\section{Education scenarios}

Table 2A shows the base year values for the education inputs and the assumptions for the end value in $\mathbf{2 0 5 0}$ for each of the scenarios. We choose Botswana as a benchmark country to set the targets for the education scenarios. For example, expected female years of education is seen to increase from eight years in 2010 to 11.74 in 2050 in the third and fourth scenarios. The base scenario target is set at one third of the increase between 2010 and 2050 . Similar assumptions apply to the other variables.

\section{Proximate determinants of fertility scenarios}

Table 2B shows the scenarios for the three proximate determinants of fertility that are explicitly modelled in DemDiv. Modern CPR was $9.8 \%$ in 2013 , based on the 2013 NDHS. Although our base year for the simulations is set at 2010 , because there has been so little change in contraceptive use since the previous NDHS we used the 2013 figure for 2010. We set the final year figure for the base scenario at $25.8 \%$, assuming that current unmet need of $16 \%$ will be met $(9.8+16=25.8$.

\section{Economic scenarios}

Since the demographic dividend is primarily an economic phenomenon that is catalysed by demographic change, it is important to understand and discuss how economic strategies are modelled. As described in more detail in the DemDiv technical report, the model has five inputs that influence the economic sub-model, all of them based on the indices of the World Economic Forum's Global Competitiveness (GCl) Report.' Of the 12 "pillars" that make up the overall $\mathrm{GCl}$, the DemDiv model includes five of these, or elements of those five. They are indices that measure the quality of public institutions, imports as a percent of GDP (to measure trade openness), ICT infrastructure, labour market flexibility and financial market efficiency.

The $\mathrm{GCl}$ report distinguishes three stages in a country's development: stage I countries are seen as "factor driven" economies; stage 2 are "efficiency driven" economies; stage 3 countries are "innovation driven." In 2012, Nigeria overall GCl index puts it 117th out of 148 countries. This places Nigeria among the "stage I" or "factor-driven" countries. The country ranks $129^{\text {th }}$ for infrastructure, 135 for institutions and almost last at 146 for health. However, in terms of macroeconomic environment it ranks $46^{\text {th }}$.

To choose the target year values of the $\mathrm{GCl}$ policy variables for the model for the scenarios that modelled an economic emphasis, we compared the values of the $\mathrm{GCl}$ variables for Nigeria against the average for Stage 2 and Stage 3 countries. If the 
Nigerian indicator was below the Stage 2 value we set the target at the stage 2 value. If the value was between Stage 2 and Stage 3, we set the target at the Stage 3 average. Values for the base scenario were set at the initial value plus one third of the change between the base year and final year target values. Final target values are shown in Table 2C

Table 2A: Scenario Inputs: Education

\begin{tabular}{|c|c|c|c|c|c|c|}
\hline SCENARIO & $\begin{array}{l}\text { YEAR } \\
\text { YEAR }\end{array}$ & $\begin{array}{l}\text { Expected } \\
\text { Years } \\
\text { (Female) }\end{array}$ & $\begin{array}{l}\text { Expected Years } \\
\text { (Male) }\end{array}$ & $\begin{array}{l}\text { Mean Years } \\
\text { (Female) }\end{array}$ & $\begin{array}{l}\text { Mean Years } \\
\text { (Male) }\end{array}$ & $\begin{array}{l}\text { Mean Years } \\
\text { (Both) }\end{array}$ \\
\hline & 2010 & 8.16 & 9.76 & 5.27 & 6.68 & 5.98 \\
\hline Base & 2050 & 9.35 & 8.79 & 6.41 & 7.47 & 6.94 \\
\hline Econ Only & 2050 & 9.35 & 8.79 & $6.4 I$ & 7.47 & 6.94 \\
\hline Econ + Educ & 2050 & 11.74 & 11.64 & 8.68 & 9.06 & 8.87 \\
\hline$E c o n+E d+F P$ & 2050 & 11.74 & 11.64 & 8.68 & 9.06 & 8.87 \\
\hline & & $\begin{array}{l}\text { SOURCE: UN } \\
\text { Table } \\
2010 \\
\text { **Future values } \\
\text { data for S } \\
\text { countries }\end{array}$ & 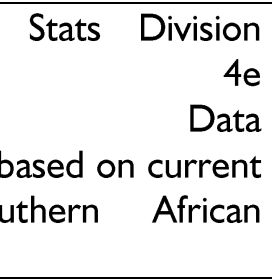 & \multicolumn{3}{|c|}{$\begin{array}{l}\text { SOURCE: Barro \& Lee Database, } 2014 . \\
201 \mathrm{l} \text { data from UNESCO } \\
\text { **Future values based on current data for } \\
\text { Southern African countries }\end{array}$} \\
\hline
\end{tabular}

Table 2B: Scenario Inputs: Proximate Determinants of Fertility

\begin{tabular}{|l|l|l|l|l|l|}
\hline & & $\begin{array}{l}\text { CPR Modern } \\
\text { (Married } \\
\text { Women) }\end{array}$ & $\begin{array}{l}\text { CPR Traditional } \\
\text { (Married } \\
\text { Women) }\end{array}$ & $\begin{array}{l}\text { Postpartum } \\
\text { Insusceptibility } \\
\text { (Months) }\end{array}$ & $\begin{array}{l}\text { Sterility } \\
\text { (Percent Women 45-49) }\end{array}$ \\
\hline YEAR & 2010 & 9.8 & 5.4 & 12.6 & 3 \\
\hline Base & 2050 & 25.8 & 4.0 & 12 & 3 \\
\hline Econ Only & 2050 & 25.8 & 4.0 & 12 & 3 \\
\hline Econ + Educ & 2050 & 25.8 & 4.0 & 12 & 3 \\
\hline Econ + Ed + FP & 2050 & 65.0 & 2.5 & 9 & 3 \\
\hline & \multicolumn{7}{|l|}{$\begin{array}{l}\text { SOURCE: Demographic and Health Survey } \\
\text { PPI based on 20I3 value for Lagos. }\end{array}$} \\
\hline
\end{tabular}

Table 2C. GCI Values for Nigeria and Stage 2 and 3 Countries and Model Targets

\begin{tabular}{|c|c|c|c|c|c|}
\hline $\begin{array}{l}\text { Upper Middle Income Benchmark } \\
\text { Countries }\end{array}$ & $\begin{array}{l}\mathrm{GCl} \text { IA } \\
\text { Public } \\
\text { Institutions }\end{array}$ & $\begin{array}{l}\text { GCl } 6.14 \\
\text { Imports } \\
\% \text { of } \\
\text { GDP }\end{array}$ & $\begin{array}{l}\text { GCl 7A } \\
\text { Labor } \\
\text { Market } \\
\text { Flexibility }\end{array}$ & $\begin{array}{ll}\mathrm{GCl} & 8 \mathrm{~A} \\
\text { Financial } & \\
\text { Market } & \\
\text { Efficiency } & \end{array}$ & $\begin{array}{ll}\mathrm{GCl} & 9 \mathrm{~B} \\
\mathrm{ICT} & \text { Use } \\
(4) & \end{array}$ \\
\hline Nigeria 20|3-20|4 & 3.08 & 27 & 4.53 & 4.03 & 1.67 \\
\hline Average for Stage 2 Countries 20I3-20I4 & 3.59 & 45.9 & 3.60 & 3.63 & 2.30 \\
\hline Average for Stage 3 Countries 2010 & 4.9 & 61.8 & 4.62 & 4.67 & 5.63 \\
\hline Targets for Model in 2050 & 4.9 & 45.9 & 4.62 & 4.67 & 3.85 \\
\hline
\end{tabular}

\section{Results of the Modelling Scenarios}

Results of the four simulations are summarized in Table 3. In terms of demographic changes we can see that under the Base Scenario and the Economic Only Scenario that the TFR decreases over the 40 year projection period by about one birth per woman to 
4.4. This is because the assumed end period modern CPR increases only to 25.8. This results in a projected population of 209 million in 2050 and a dependency ratio of 0.71 , only slightly lower than the base year ratio of 0.709 . Under the Economic and Education Scenario, the TFR is slightly lower than in the Base Scenario because with increased girls' education the percent of women married decreases and this decreases the TFR. The resulting total population in 2050 is 197 million under this scenario and the dependency ratio down to 0.68 by the year 2050. Under the more aggressive Combined Scenario, (column 6 of Table 3), in which modern CPR is assumed to reach $65 \%$ by 2050 , the TFR falls to 2, and total population reaches 157 million and difference of 57 million compared to the Base and Economic Only scenarios. The dependency ratio is lower still at 0.46 .

Turning next to the economic Impacts of the four scenarios we can see that investment per capita increases from $\$ 350$ in 2010 to $\$ 754$ in the Base Scenario, a more than 2 fold increase and to $\$ 1640$ in the Economic Only Scenario, nearly 5 fold. In the Economic and Education and Combined scenarios the figure is $\$ 1,836$ and $\$ 2,544$ respectively. Hence, investment per capita is some $40 \%$ higher in the final year as a result of the more aggressive family planning scenario. The main reason that investment is so much higher in the Combined Scenario is because of the more favourable age distribution as shown by the lower dependency ratio.

In terms of GDP and GDP per capita, we see similar gains to family planning when we compare the Economic and Education to the Combined Scenario. GDP in the final year is $1.6 \%$ higher and GDP per capita is $27 \%$ higher".

As mentioned earlier, there are other models that have recently been developed to study the demographic dividend and some have been applied to Nigeria. Comparison of different models should only be done if the same scenarios are compared, but we did not have access to other models, only to results as reported and so the scenarios, while similar are not exactly the same. Nevertheless, a review of results of three other models shows that, if using per capita income as a measure of the demographic dividend, the model presented here shows lower percentage changes. The study of Bloom et.al. (2013) projects a $43 \%$ increase in per capita incomes by 2050, while a similar study by the same author published by the World Economic Forum in 2014 shows a $29 \%$ demographic dividend after 20 years. Lastly results shown by Canninget.al. (2015) show a very large $84 \%$ increase in GDP per capita in 2050 of lower fertility.

Table 3 Key Indicators by Scenario

\begin{tabular}{|c|c|c|c|c|c|}
\hline 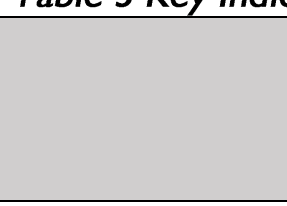 & $\begin{array}{l}\text { Base year } \\
2010\end{array}$ & $\begin{array}{l}\text { Base Scenario, } \\
2050\end{array}$ & $\begin{array}{l}\text { Economic } \\
\text { Only } \\
\text { Scenario, } \\
2050\end{array}$ & $\begin{array}{l}\text { Economic \& } \\
\text { Education } \\
\text { Scenario, } 2050\end{array}$ & $\begin{array}{l}\text { Combined } \\
\text { Economic, } \\
\text { Education \& FP } \\
\text { Scenario, } 2050\end{array}$ \\
\hline CPR-Modern & 9.8 & 25.8 & 25.8 & 25.8 & 65 \\
\hline TFR & 5.5 & 4.4 & 4.4 & 4 & 2 \\
\hline $\begin{array}{l}\text { Population } \\
\text { (million) }\end{array}$ & 83.9 & 209 & 209 & 197 & 157 \\
\hline $\begin{array}{l}\text { Dependency } \\
\text { Ratio }\end{array}$ & 0.79 & 0.71 & 0.71 & 0.68 & 0.46 \\
\hline $\begin{array}{l}\text { Investment per } \\
\text { capita }\end{array}$ & $\$ 350$ & $\$ 754$ & $\$ 1,640$ & $\$ 1,836$ & $\$ 2,544$ \\
\hline Employment & 46.7 & 113.3 & 127.2 & 123.1 & 114.7 \\
\hline GDP (billion) & $\$ 91.9$ & $\$ 487.8$ & $\$ 1,142.0$ & $\$ 1,206.0$ & $\$ 1,226.0$ \\
\hline GDP per capita & $\$ 1,095$ & $\$ 2,333$ & $\$ 5,464$ & $\$ 6,108$ & $\$ 7,786$ \\
\hline
\end{tabular}

\section{Discussion and Conclusions}

Results of simulating four scenarios with a twocomponent economic-demographic model show that Nigeria can expect to transition from a lower to a higher middle income country in $\mathbf{4 0}$ years if it adopts strategies that emulate those of other countries that are currently in the middle income range. Moreover, by adopting a more ambitious family planning program, if combined with policies to improve girls' education, it can expect further gains in GDP and 
GDP per capita. These additional gains constitute a demographic dividend for Nigeria as it lowers its fertility with resulting changes in the age structure.

But achieving the demographic dividend requires not only strategies that improve access to and use of family planning and girls' education, but also economic and governance policies that support an economic environment which can capitalize on the more favourable demographic situation. Such policies include a more efficient financial market; a more flexible labour market; improvement in the openness and transparency of public institutions; significant improvements in ICT infrastructure and access to it, and a more open economy internationally.

Reducing population growth and changing the age structure is not a panacea for economic development in Nigeria. But as the model's results suggest, lowering the rate of population growth can act as a boost to economic growth when combined with other strategies such as education, economic reform and ICT infrastructure. In conclusion, the simulation modelling exercise suggests that Nigeria can benefit from a demographic dividend if it chooses the right combination of social, health and economic strategies, including investments in education as discussed above.

\section{References}

Bloom, D.E. and Williamson, J.G. (1998), Demographic Transitions and Economic Miracles in Emerging Asia. World Bank Economic Review, I2(3), 419-455.

Bloom, David E., Salal Humair, Larry Rosenberg, JP Sevilla, and James Trussell, A Demographic Dividend for Sub-Saharan Africa: Source, Magnitude and Realization, unpublished manuscript, 2013

Bloom, David E., Salal Humair, Larry Rosenberg, JP Sevilla, and James Trussell, The Demographic Dividend of Meeting Unmet Need for Modern Contraception in Sub-Saharan Africa, presentation made at PAA 20I4, Boston MA, May I-3, 2014

Canning, David, Mahesh Karra, Joshua Wilde, A Macrosimulation Model of the Effect of Fertility on
Economic Growth: Evidence from Nigeria, unpublished paper, April 27, 2015.

Drummond, P., Thakoor, V., \& Yu, S. (20I4). Africa Rising: Harnessing the Demographic Dividend. International Monetary Fund Working Paper.

Gribble, James N. and Jason Bremner, Achieving a Demographic Dividend, Population Bulletin 67, no. 2 (20I2).

Kelley, Allen C., The Population Debate: A Status Report and Revisionist Interpretation, in The New Population Debate 7, ed. Paola M. Scommegna (Washing-ton, D.C.: Population Reference Bureau, 1985), pp. I2-23;

King, Timothy, Population and Development: Back to First Principles, in Scommegna, ed., pp. 2-II;

McNicoll, G., Consequences of Rapid Population Growth: Over-view and Assessment, Population and Development Review 10 (1984): 177- 240; and World Bank, World Development Report (New York: Oxford University Press, 1984).

Moreland, S., Madsen, E.L., Kuang, B., Hamilton, M., Jurczynska, K. \& and Brodish, P. (20I4). Modeling the Demographic Dividend: Technical Guide to the DemDiv Model. Washington, DC: Futures Group, Health Policy Project.

National Academy of Sciences, Population Growth and Economic Development: Policy Questions, National Academy Press, Washington, D.C. 1986

Schwab, Klaus, Editor, and Xavier Sala-i-Martín, The Global Competitiveness Report 2013-2014, World Economic Forum, 2013

United Nations, 2015 Revision of World Population Prospects, 2015

World Economic Forum, Prospects for Reaping a Demographic Dividend in Nigeria, 2014

World Economic Forum. (2014). Global Competitiveness Index. Retrieved from http://reports.weforum.org/globalcompetitiveness-report-2014-2015/rankings/. Accessed 6 March 2015.

World Bank, http://data.worldbank.org/indicator/NY.GDP.PCA P.CD, accessed 3.29.2016

\section{End notes}

ii The economic data used to construct the economic model were taken largely from the World Bank data bank when the research to estimate the model was conducted in 2013-2014. Since then, the economic data have been revised and show a different level of GDP and GDP per capita. However, for the simulations reported her we have not updated those data. 